\title{
COCKATIELS: A NOVEL ANIMAL MODEL FOR STUDYING THE EVOLUTION OF MUSIC AND LANGUAGE
}

\author{
YOSHIMASA SEKI \\ yoshimasa.seki@gmail.com \\ Department of Psychology, Aichi University, Toyohashi, Japan
}

In view of the connections between music and language (Wallin et al., 2001), it is possible that research on the musical performance of animals could increase our understanding of the evolution of human language. Songbirds, such as zebra finches, which are widely used in lab experiments, are occasionally described as a model species for human musicality research. However, with some exceptions (e.g., bullfinches; Nicolai et al., 2014), members of this species seldom copy human music. Additionally, birdsong may differ substantially from human music (Araya-Salas, 2012). Meanwhile, spontaneous entrainment to various beats of human music by two parrots (Snowball and Alex) has been reported (Patel et al., 2009; Schachner et al., 2009). Thus, parrot species are potential and alternative candidates for the study of human music capabilities and evolutionary adaptation.

This study focuses on the cockatiel (Nymphicus hollandicus), a small cockatoo (parrot) species. While it is well known that some parrot species are excellent at imitating human speech, the cockatiel is characterized by its spontaneous imitation of human musical sounds using whistle-like vocal sounds, such as those heard in the Mickey Mouse Club March. This characteristic is well known by bird lovers (e.g. more than 2,500 search results were found for the key phrase " "cockatiel" "mickey mouse march" ' on YouTube; as of Jan 2018); however, scientific studies evaluating vocal behavior in this species are limited.

I raised four cockatiel chicks that were exposed to the whistle sounds (an average of fewer than 5 times/day) of the Mickey Mouse Club March. At 100 days post-hatch, three birds began to imitate the melody of the music. In the beginning, the birds would produce a short phrase, followed by another short phrase. The birds would then concatenate the short phrases and eventually complete the full piece with a slight alteration of the melody to a phrase. Two also 
imitated several human words, but the other never did so, suggesting that the capability for vocal learning and that for imitating musical sounds may be independent of each other. The musical sounds were often produced immediately after the birds were left alone. Thus, although males seemed to be good at such mimicry, they may use these sounds to attract the attention of humans rather than as part of courtship behavior. Moreover, some birds showed a spontaneous "quick head shaking" during playback of human music. The timing of the behavior was analyzed to evaluate the rhythmic entrainment to the stimulus sounds. The results indicated a kind of regularity, but more evidence is needed to reach firm conclusions in this regard.

\section{Acknowledgements}

Supported by MEXT/JSPS KAKENHI JP25285198, JP17H06383 in \#4903.

\section{References}

Wallin, N. L., Merker, B., \& Brown, S. (Eds.). (2001). The origins of music. Cambridge, MA: MIT press.

Nicolai, J., Gundacker, C., Teeselink, K., \& Güttinger, H. R. (2014). Human melody singing by bullfinches (Pyrrhula pyrrula) gives hints about a cognitive note sequence processing. Animal Cognition, 17, 143-155.

Araya-Salas, M. (2012). Is birdsong music? Evaluating harmonic intervals in songs of a Neotropical songbird. Animal Behaviour, 84, 309-313.

Patel, A. D., Iversen, J. R., Bregman, M. R., \& Schulz, I. (2009). Experimental evidence for synchronization to a musical beat in a nonhuman animal. Current Biology, 19, 827-830.

Schachner, A., Brady, T. F., Pepperberg, I. M., \& Hauser, M. D. (2009). Spontaneous motor entrainment to music in multiple vocal mimicking species. Current Biology, 19, 831-836. 